\title{
DEL ARTE DEL RECUERDO (II) LUGARES DEL CONOCIMIENTO Y MÁSCARAS DE LAS ARTES
}

\section{ABOUT THE ART OF MEMORY (II) PLACES OF KNOWLEDGE AND MASKS OF THE ARTS}

\author{
ELENA MuÑoz GÓMEZ \\ Universidad de Salamanca
}

Recibido: 14/07/2019 Aceptado: 10/10/2019

\section{RESUMEN}

En este artículo se presenta un muestrario de lugares e imágenes del saber sobre las artes. Son representaciones visuales en manuscritos, esculturas, estampas, con esquemas, símbolos, personificaciones, historias, artefactos mnemotécnicos que usan letras y palabras como figuras, o descripciones alegóricas que promueven la memorización de sus contenidos a través de mecanismos visuales. A pesar de la variedad, la difusión y los distintos usos de este tipo de 'imágenes del conocimiento', es posible entenderlas en relación con las teorías del arte de la memoria y sus loci et imagines, que pudieron funcionar como estructuras mentales configurando otras representaciones en las artes plásticas y en la literatura.

Palabras clave: Arte de la Memoria, Historia del arte, Artes, Literatura, Edad Media.

\section{ABSTRACT}

This article presents a sample of places and images of knowledge about the arts. These are visual representations in manuscripts, sculptures, prints, with schemes, symbols, personifications, histories, mnemonic artefacts that use letters and words as figures, or even allegorical descriptions that promote the memorization of their content 
through visual mechanisms. Despite of the variety, the wide diffusion, and the different uses of these 'images of knowledge', it may be posible to undestand them in relation to the specific theories of the 'art of memory' and its loci et imagines, that could work as mental structures configuring other representations in the plastic arts and literature.

Keywords: Art of Memory, History of Art, Arts, Literature, Medieval Age 
En este artículo se presenta la segunda parte de un estudio de aproximación al arte memorativa. Allí se comentaron investigaciones precedentes sobre las raíces clásicas de este arte, transformaciones medievales de algunas de sus reglas y elementos, y cómo se practicaba para recordar ${ }^{1}$. En torno a la memoria artificicial se planteó el problema de colaboración entre artes visuales y artes de la palabra, y se consideró la posibilidad - a partir de trabajos de historiadores del arte como Erwin Panofsky, Serafín Moralejo, Rocío Sánchez o Lucía Lahoz- de que ciertas imágenes representadas en obras plásticas pudiesen ser pensadas en clave de normas poéticas y retóricas en un contexto. Sin tratar de establecer relaciones de influencia directa o copia entre imágenes y textos del arte de la memoria u otras manifestaciones artísticas, aquí proseguimos observando el proceso que lleva al lado en cierto modo opuesto, y va desde esas imágenes mnemotécnicas a obras literarias donde se hagan notar efectos de las reglas de estas artes visuales.

\section{OTRA INTRODUCCIÓN AL ARS MEMORIAE}

Según teorías medievales, la memoria es un vínculo matérico-espiritual que liga el movimiento físico e intelectual de los hombres conectando su alma y su cuerpo. Los seguidores escolásticos de Cicerón diferenciaban dos tipos de memoria: la memoria natural que tienen todos los animales como capacidad innata, y la que sólo el hombre puede educar a base de ejercicios mnemotécnicos: la memoria artificial. Esta se desarrolla principalmente gracias a la visión interna (que funciona como una pantalla de la mente) y externa (la visión del órgano de los ojos). El arte de la memoria consiste en construir imágenes mentales a partir de imágenes externas, estructurarlas, y retenerlas en las puertas del olvido para rescatarlas y convertirlas en expresiones actuales. Este arte pone en juego tanto la memoria de cosas (el recordar conceptos y nociones) como de palabras, pero siempre por mediación de imágenes. La visión de una imagen es entendida como una lectura o recolección de lo ya ideado o tenido en mente ${ }^{2}$.

1 Publicado en el número 37 de esta revista (Muñoz 2017: 71-90), esta segunda parte ha sido también desarrollada bajo el proyecto doctoral MECD-FPU17/03735 dirigido por Lucía Lahoz en el Departamento de Historia del Arte y Bellas Artes de la Universidad de Salamanca (USAL). Una síntesis de ambos artículos fue presentada en las I Jornadas sobre Intermedialidad e Institución del proyecto MINECO-HAR2017-85392-P, 2018-2020, dirigido por Fernando González (Facultad de Geografía e Historia, USAL, 22-23/11/2018).

2 Entre otros estudios citados en aquella aproximación, ver Yates, 1966a; Carruthers, 1992; Coleman, 1992; Carruthers/Ziolkowski, 2003; Wenzel, 2015, Morcillo, 2015, y pese a quedar pendiente en esta ocasión la revisión de su obra, añadimos a De la Flor, 1995, especialmente pp. 109-179, cuyas referencias amplían los recursos bibliográficos para el estudio de la memoria artificial. 
«(...) Para una memoria instruida, dos cosas son necesarias: lugares estables e imágenes de la materia. Los lugares son como las tablas donde escribimos, y las imágenes son como letras escritas en ellas. Los lugares son permanentes y fijos mientras que las imágenes son entintadas como letras y al momento borradas. Los lugares son los fondos, y deben ser hechos antes que las imágenes» ${ }^{3}$.

En el arte memorativa, para la construcción del objeto que se quiere memorizar, se utilizan imágenes y lugares. En cada lugar se instalan las imágenes de las cosas que se quieran recordar por sus figuras o sus nombres, en cualquier caso ubicadas sobre esa estructura de fondo (que también es una imagen). La palabra personis (máscara y persona) se usaba para aludir a las imágenes propias de la memoria de cosas, y ello lleva a reflexionar acerca de cómo la imagen exagera el aspecto del recuerdo, recordar consistiría en algo parecido a investirse con una máscara y la memoria funcionaría como un teatro mental o juego de representaciones ${ }^{4}$. Durante la Edad Media los loci solían tomar formas reconocibles para sus usuarios: figuras de edificios, árboles, querubines con alas donde insertar conceptos, virtudes, por ejemplo, imágenes dirigidas a estudiosos de la memorización y la predicación. Otro punto a recordar de esta Memoria artificial es su relación con las normas de la retórica y la moral bajo la doctrina teológica; Memoria es la virtud correspondiente al pasado, una de caras de Prudencia, junto a Inteligencia y Providencia. Pero había muchas teorías y aplicaciones memorativas, algunas prohibidas.

\section{LUGARES DEL SABER Y MÁSCARAS DE LAS ARTES}

Rolando Carrasco, en un estudio enfocado desde la literatura, se preguntaba si algunas producciones ajenas a las artes de la memoria pudieran representar a su manera el teatro memorativo o 'topografía mental' de las prácticas mnemotécnicas, y hasta qué punto estas eran capaces de condicionar narrativas mediante el efecto persuasivo y metafórico de sus imágenes (1999). Aunque las imágenes y lugares, o contenidos y estructuras memorativas, se hayan plasmado en impresos y manuscritos que circularon de manera restringida y se idearon para su contemplación e interiorización individual en las escuelas y monasterios, el caso es que la memorización de algo es el fundamento de una expresión nueva, de modo que, esos lugares y máscaras, pudieron promover imágenes de otros medios, soportes y discursos. El clero, que memorizaba esos esquemas

3 Thomas Bradwardine, De cómo adquirir una memoria instruida (c. 1300), en Carruthers, 1992: 25-43 y Carruthers/Ziolkowski, 2003: 207.

4 Sobre los teatros memorativos de Giulio Camillo y Robert Fludd, Yates, 1966a:129-172, 342-367, y 1966b. 
conceptuales, era mediador de la Palabra y transmitía el saber a otros, en sermones o en diseños monumentales que explican un conocimiento en un código visual adaptado a audiencias más multitudinarias. En este sentido abierto se puede hablar de lugares de conocimiento para referirnos aquí a este amplio tipo de imágenes con una marcada función didáctica y memorativa, que trasponen relaciones semánticas y sintácticas a través de un sistema de relaciones entre fondos y figuras (vid. Flores, 2011: 1-14).

Cualquier palabra o significado puede ser memorizado a través de imágenes. Las cartas o Applicationes del tratado de Logica memorativa de Thomas Murner, componen un diccionario figurativo que sistematiza metáforas, equivalencias de imágenes y significados, para explicar un contenido con figuras interrelacionadas en composiciones lógicas. En la octava aplicación, por ejemplo, los elementos gramaticales de enunciatio y propositio son un collar en la lengua, y la Imposibilidad es un 'demonio con nimbo's. Gombrich observó que, para aprenderse como sistemas lógico-técnicos o disciplinas, desde la Antigüedad, las clases del conocimiento se imaginan en diseños figurativos que configuran, a la vez, sistemas de disposiciones simbólicas que los explican, y se trasponen en iconografías que se leen, no sólo en los tratados de la memoria. Son composiciones con mucho peso semántico, de figuras articuladas por una especie de sintaxis visual. En estas imágenes -advertía el historiador del arte- notablemente confluyen las funciones «representativa, simbólica y expresiva». Así procuraba distinguir los mecanismos que activan el «extraño modo en que la literatura y el arte occidentales han preservado el peculiar hábito del mundo antiguo de 'hipostasiar' conceptos abstractos». Según Gombrich, las personificaciones, como la dama de la Gramática, dotan a los nombres de un género (femenino) que impide distinguirlos de las 'cosas vivas', y estas máscaras se convierten en abstracciones. Si el arte clásico asociaba cada divinidad a una personificación y una metáfora, las alegorías plásticas -decía Gombrich-son representaciones expresivas de una cosa abstracta que, al mismo tiempo, la explican, y cuya explicación empuja a la imaginación «a alcanzar una expresión más perfecta» de ese conocimiento (1972: 216-218).

Cada imagen del saber, aun ajena al arte memorativa, compone su mapa de hipóstasis para el aprendizaje y el recuerdo, donde cada parte puede ser subdividida como un microcosmos. El Libro de Tübingen, del siglo XV (Fig. 1) ${ }^{6}$,

5 Thomas Murner, Logica memorativa, Argentoratum, 1509, Bayerische Staats-Bibliothek, Munchen, Rar. 1455, p. 41. Vid. Reinik/Stumpel, 2012.

6 Tübingen Hausbuch: Iatromathematisches Kalenderbuch; die Kunst der Astronomie und Geomantie, Württemberg, ¿Ulm?, 1430-1480, Biblioteca de la Universidad de Tübingen, Md/2, f. 320v. Gracias al profesor Manuel González de Ávila por el encuentro con esta obra. 
tiene en común con los productos memorativos, al menos, el empleo de signos e imágenes simbólicas que contienen y explican contenidos herméticos, de geomancia, astrología. El manuscrito se ilustra con los siete planetas asociados a las artes liberales y elementos de la alquimia, situados en el lugar de un edículo almenado. La forma triangular de esta estructura facilita la jerarquización de las máscaras de las artes que se instalan en ella: De izquierda a derecha y de abajo a arriba asoman la Geometría, la Lógica y la Aritmética; de derecha a izquierda, desde el otro lado, la Música, la Física y la Retórica. La Gramática corona la arquitectura en el vértice, sobre el astro solar. Es una explicación del Trivium y el Quadrivium adaptada al tema del tratado. Pero las imágenes de este cosmos no siempre aparecen dispuestas en el mismo orden, ni se refieren al mismo campo semántico, y la estructura del lugar en el que se inscriben tampoco es lo único que condiciona el modo en que se jerarquizan para significar. El Hortus deliciarum de Herrad von Landsberg estaba diseñado para las monjas de la abadía Mont Sainte-Odile, en Ottrott, a fines del siglo XII (Fig. 2). En él aparecen las mismas artes personificadas de otro modo, en otro lugar. La rueda o rosa que hace de fondo, ubica las figuras a la misma distancia del centro y con ello las iguala en importancia; pero la situación de otras imágenes anejas en la composición, la posición vertical de la propia página y la dirección horizontal de la escritura, colocan a la Gramática de nuevo arriba, mientras el centro de la rueda se reserva a máscaras medievales de filosofía clásica? ${ }^{7}$.

En este tipo de representación en manuscritos didácticos, la interpretación de la imagen plástica está dirigida por la escritura y los diseños facilitan la memorización enriqueciendo los contenidos textuales. Son productos de alta cultura, y sus enseñanzas pudieron promover iconografías en otros soportes. La Gramática en el tímpano del pórtico Royal de la catedral de Chartres sigue representada con los mismos atributos, como «ciencia que enseña a hablar correctamente, fundamento de las letras $\rangle^{8}$; su fusta o escoba simboliza la instrucción inicial. Como decía Gombrich, la alegoría de la Gramática es la Dama de la Gramática y explica y representa a la Gramática. En Chartres aparece al lado de la Música y supeditada al programa mariológico y escolar de esa portada, al medio escultórico y al soporte monumental que hace de 'puerta escénica' al edificio religioso de una comunidad ${ }^{9}$.

7 Philosophia et septem artes liberales, f. 32 r. del Hortus Deliciarum, ca. 1170 CE, Strasbourg. Extraemos la p. 8 del Herrad von Landsperg, Aebtissin zu Hohenburg, oder St Odilien, im Elsass, im zwölften Jahrhundert und ihr Werk, Hortus deliciarum... de Christian Maurice (Moritz) Engelhardt, editado por J-G Cotta (Stuttgart Tübingen) en 1818, conservado en la Biblioteca Nacional Francesa (BNF 41904838).

8 Isidoro de Sevilla, Etimologías, Reta/Casquero/Díaz (eds.), 2004: 277.

9 Spitzer, 1994: 132-150; Storrs, 1997: 27. 


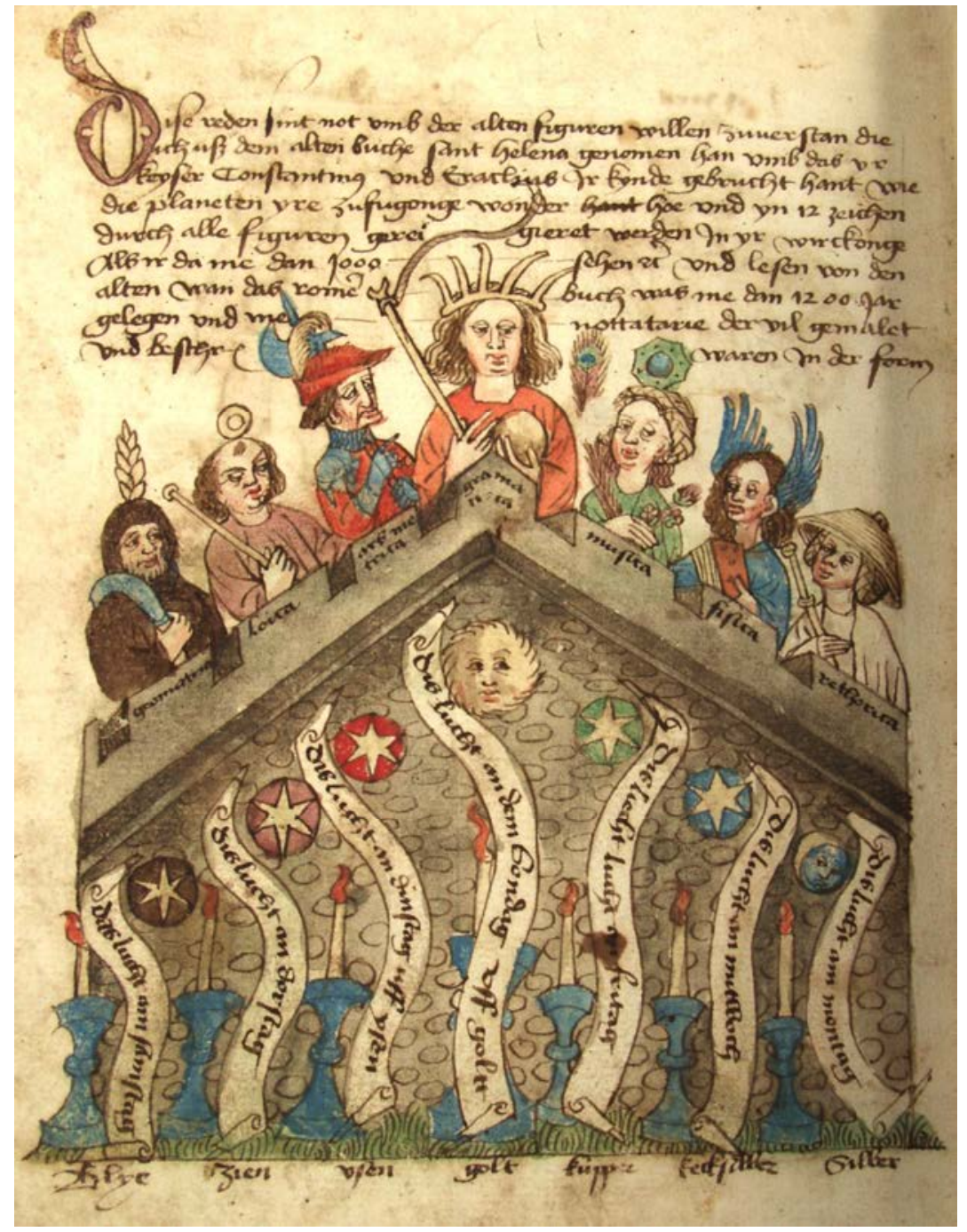

Fig. 1. Tübingen Hausbuch: Iatromathematisches Kalenderbuch; die Kunst der Astronomie und Geomantie, Württemberg, ¿Ulm?, 1430-1480, Biblioteca de la Universidad de Tübingen, $\mathrm{Md} / 2$, f. $320 \mathrm{v}$. 


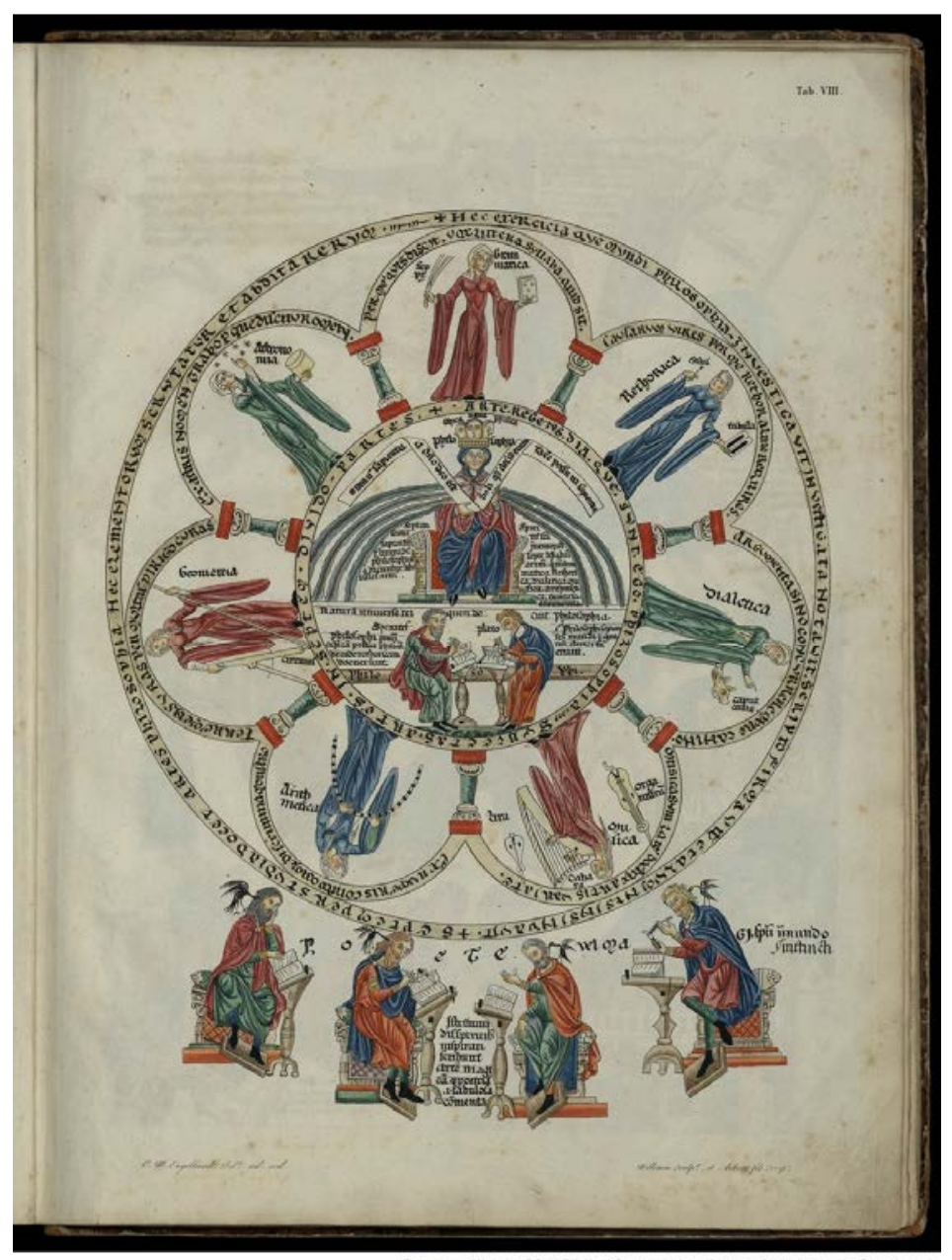

Fig. 2. Philosophia et septem artes liberales, f. 32r. del Hortus Deliciarum, ca. 1170 CE, Strasbourg, extraído del Herrad von Landsperg, Aebtissin zu Hohenburg, oder St Odilien, im Elsass, im zwölften Jahrhundert und ihr Werk, Hortus deliciarum... de Christian Maurice (Moritz) Engelhardt, editado por J-G Cotta (Stuttgart Tübingen) en 1818, p. 8. Biblioteca Nacional Francesa (BNF) 41904838. 


\subsection{ARTES EN EDIFICIOS}

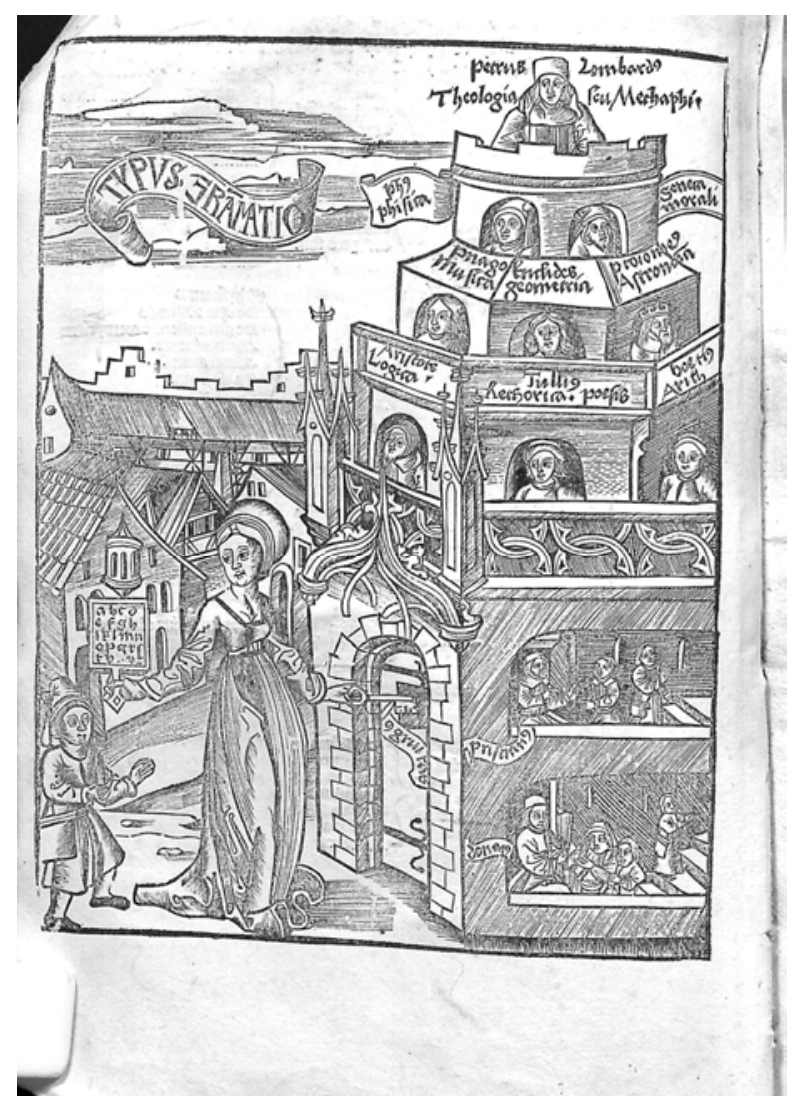

Fig. 3. Gregor Reisch, Typus Grammaticae Margarita philosophica nova cui insunt sequentia..., Argentine, Joannes Grüningerus, 1512, Biblioteca de Castilla-La Mancha, Res.695 (1), p. 11.

Los códigos de comunicación visual de estos contenidos a veces se sofistican para denotar relaciones más complejas. Las artes ilustradas en el Margarita philosophica de Gregor Reisch (tratado enciclopédico editado en latín hacia 1503) van encabezadas por la Prudencia, la máscara de tres caras de la que hablaba Cicerón. A ella le sigue, en el Margarita, la Gramática, como principio 
de la ciencia (Fig. 3) ${ }^{10}$. Su lugar contiene y explica las demás artes, de las que es el fundamento. Este lugar es una Turris sapientiae, otro tipo de edículo o capilla del conocimiento necesario para ser prudente: conocer lo pasado (Memoria), entender el presente (Inteligencia) y prevenir lo futuro (Providencia). En la xilografía, Nicóstrata abre la puerta al recién llegado con las llaves de la Gramática, para que entre a la torre donde moran Donato y Prisciano, y suba por la Lógica, la Retórica y la Aritmética, la Música, la Geometría y la Astrología, la Física y la Moral hasta llegar a la Teología de Pedro Lombardo. Cada disciplina está personificada en un sabio autorizado: Cicerón (retórico), Aristóteles (lógico), Séneca (moralista), figuras de saberes que, para comunicarse, podrían haberse sustituido por palabras en un esquema, como ocurre en la página siguiente del libro. La palabra también adquiere contenidos semánticos y potencia relaciones lógicas dependiendo de su lugar en una composición. La yuxtaposición del esquema a la ilustración de la Turris es una argucia didáctica. «Ciertamente, la memoria es más poderosamente afectada por impresiones sensoriales y especialmente por la vista, por lo tanto, algo aparece en tu memoria del mismo modo que aparece ante tu visión» ${ }^{11}$.

En otra Turris, también analizada por Mittelberg, esta de Heinrich Vogtherr el Viejo e impresa a mediados del siglo XVI, se explica la Gramática (germana) otra vez sobre las mismas estructuras arquitectónicas (Fig. 4) ${ }^{12}$. Pero los personajes aparecen ahora construyendo la torre. Su ocupación, la acción representada, relaciona la jerarquía de los elementos lingüísticos con los de una sociedad idealizada. Este ejemplo muestra claramente la sujeción de estas figuras a una iconografía de las ubicaciones y de la arquitectura, del gesto, de las vestimentas, de los oficios... Es una iconografía metafórica, disociada semánticamente del campo que significa. La imagen social dirige la explicación de la gramática sin necesidad de poner nombre a los retratos genéricos, aunque hace falta que la palabra explique el término metafórico del elemento lingüístico, así se sabe que Interiecto es el clérigo, Prepositio el escolar, Participium el burgués, Coniunctio el mercader, Adverbium, más arriba, el caballero, Pronomen el conde, y en lo alto del edificio el Verbum como rey y el emperador como Nomen. Prepositio, Ablativus y Accusativus charlan mientras Syntaxis y Orthographia construyen la torre. Etimologia es un arquero disparando a las Declinaciones y

10 Se publicaron muchas ediciones. Artistas como Durero, al parecer, se inspiraron en sus iluminaciones. Typus Grammaticae del Margarita philosophica nova cui insunt sequentia... Argentine, industrius vir Joannes Grüningerus, 1512, Biblioteca de Castilla - La Mancha, Res.695(1), pp. 11-12.

11 Thomas Bradwardine, De cómo adquirir una memoria instruida, Carrtuthers/Ziolkowski, 2003, p. 207.

12 Heinrich Vogtherr, Turm der Grammatik, Holzschnitt, estampa xilografiada en Zürich, impresa por Eustachius Froschauer en 1548, Johannes Gutenberg-Universität, Maguncia. Vid. infra. 
Prosodia sopla la corneta. En las figuras geométricas (ruedas con clases de nombres o grados de comparación), la palabra escrita adquiere significado añadido al ser vista en determinadas formas y disposiciones. Es un buen ejemplo de saber traspuesto en la imagen dinámica de una arquitectura social $^{13}$.

En estas torres, cada parte de la arquitectura se lee como una iconografía de los elementos tectónicos. En la Turris sapientiae de Jean de Metz (1475) ocurre algo parecido (Fig. 5) ${ }^{14}$. Los diseños muestran la tendencia constructiva que Panofsky detectaba en ciertas catedrales vistas como trasposiciones de estructuras del conocimiento (en su controvertida y ya clásica Arquitectura gótica y escolástica, donde se supone que cada cosa (escalera, muro, ventana, columna, torre, puerta) representa atribuciones morales $\mathrm{y}$ teológicas. En cualquier caso, son soportes con funciones tectónicas y simbólicas, sustentos de una estructura material y también sapiencial. En la Turris de Metz se entra,

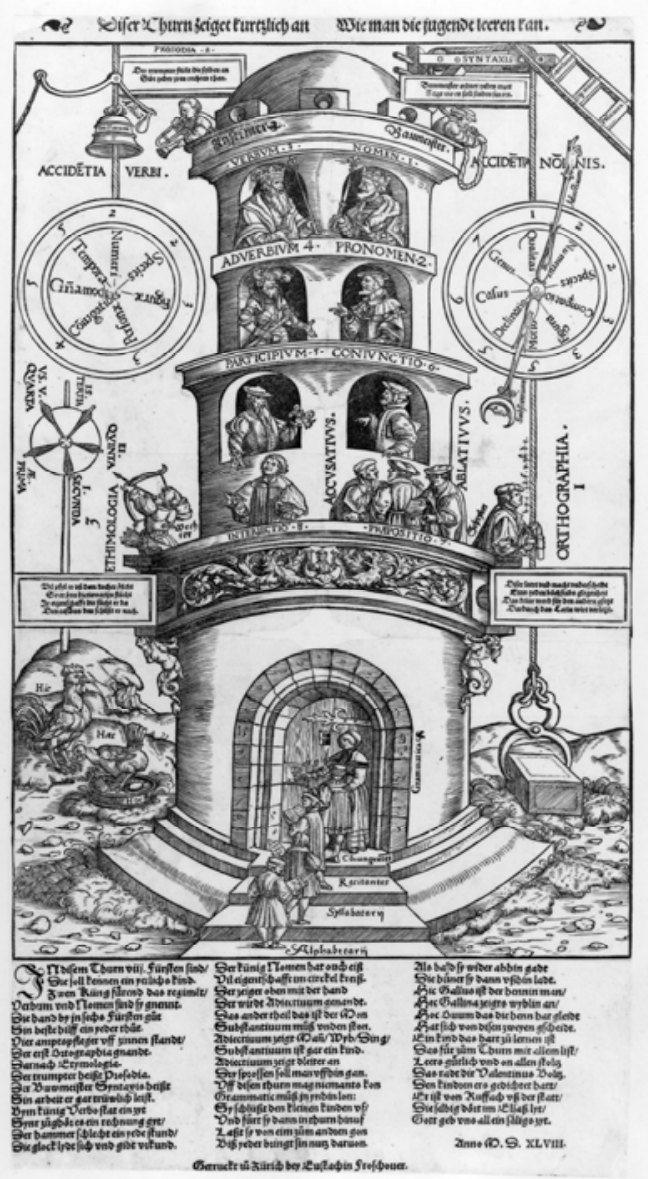

Fig. 4. Heinrich Vogtherr, Turm der Grammatik, Holzschnitt, Zürich, Eustachius Froschauer imp., 1548, Johannes Gutenberg-Universität, Maguncia. como en las Torre de la Gramática, para ascender por un tablero de saberes, pero siguiendo el orden del alfabeto. De esta manera pretende funcionar como edificio edificante. La construcción,

13 Mittelberg, 2002: 69-89 y Siegel, 2009: 116-119.

14 Johannes Metensis (Johannes von Metz) Turris sapientiae, Bod. Inc. Cat., XYL-25, f. 1r, Bodleian Library, University of Oxford. 
o la reconstrucción mental de su morfología en recorrido, quiere instruir en su saber y a la vez exponerlo.

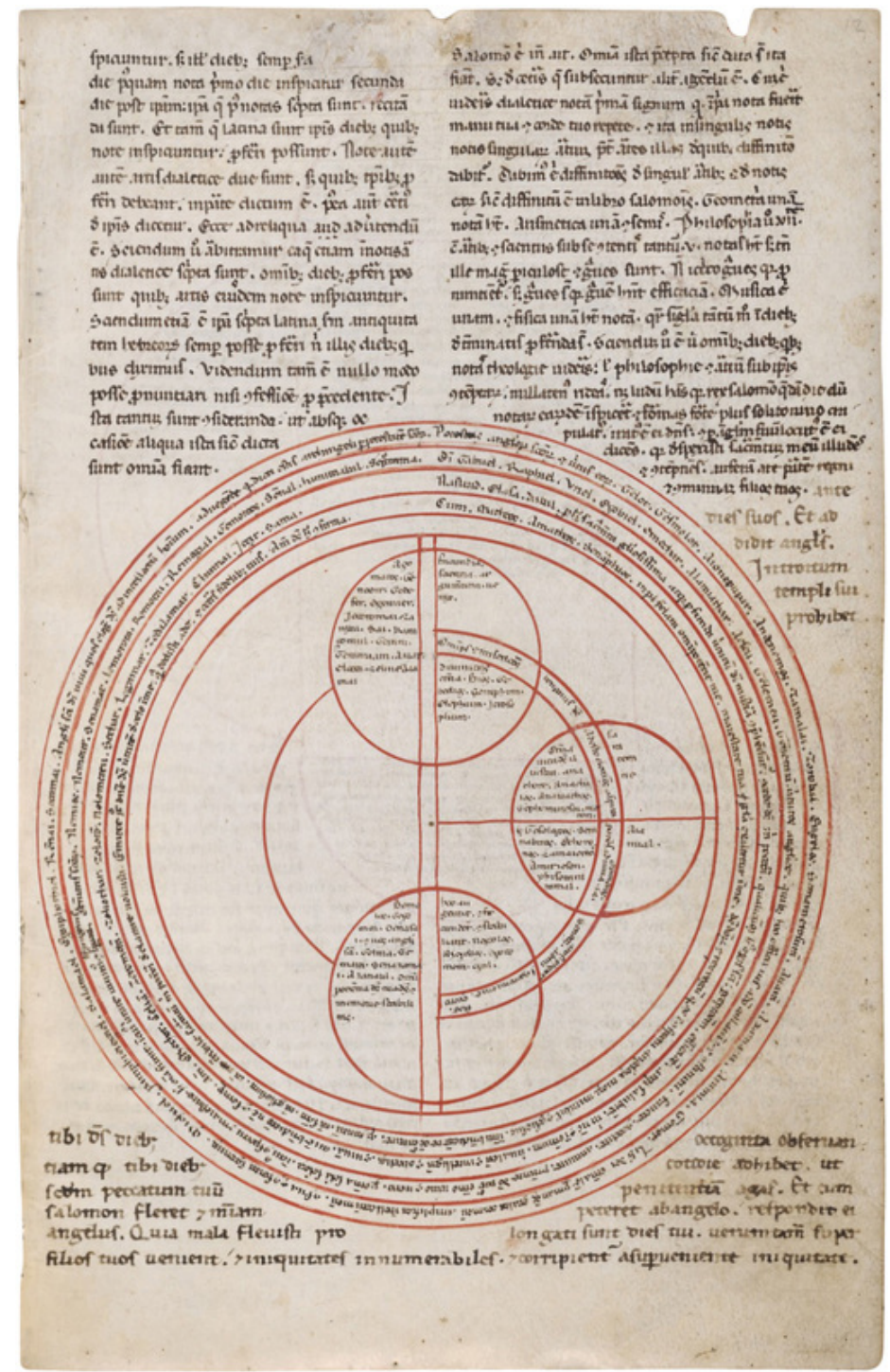

Fig. 5. Notae del Ars Notoria sive Flores aurei, ca. 1225, Mellon MS 1, Beinecke Rare Book and Manuscript Library de la Yale University. 


\subsection{LUGAR DE TODAS LAS ARTES}

Ramón Llull nació en Mallorca en el siglo XIII, alejado geográfica y culturalmente de los centros escolásticos que dictaban normas memorativas. Pero también él investigaba una problemática central para los filósofos, medievales y modernos. Como otros pensadores, concebía las artes unidas, aunque, según él, los conocimientos físicos y místicos se aprenden con vocabularios tan específicos que resulta muy difícil captar las 'verdades' que enseñan de manera directa y comunitaria. Proponía a cambio un arte general que utilizara el lenguaje de las imágenes, suponiendo que estas transparentan las estructuras de la realidad. Se han percibido en su obra influjos de teorías greco-cristianas, filosofía y lógica árabe y hebrea, y se ha dicho que su formulación de los principios del cálculo combinatorio pretendía integrar el misticismo al racionalismo, como la clavis universalis ${ }^{15}$.

En el Llibre de contemplació en Deu (1274-1276) Llull dedica un capítulo a la visión: los ojos espirituales guían a los materiales para la ascensión a lo divino desde las cosas particulares (Da Costa, 2006: 164-131), tal como argumentaban los teóricos del arte memorativa. En la Doctrina pueril (hacia 1274) ${ }^{16}$ describe ese movimiento mental que vincula la imagen al intelecto yendo de lo particular a lo general y viceversa; ese es el proceso lógico que desencadenan las artes de la memoria. Para Llull, ciencia es «saber lo que existe», y hay dos tipos: una infundida por lo divino y otra, como la memoria, puede ser educada. Pero las obras del propio Llull fueron prohibidas por la universidad parisina y la Inquisición, absueltas en el siglo XV. A partir de entonces, en términos de Elena Ausejo, dos corrientes mistificaron su obra: recogiendo su influencia filosófica, por un lado, y por otro, en la alquimia ${ }^{17}$. Aquí nos interesa de qué manera su teoría puede coincidir con las de la memoria artificial, pues compartía muchos de sus principios ${ }^{18}$.

15 La clavis de Gottfried Wilhelm Leibniz (Dissertatio de arte combinatoria, in qua ex arithmeticae fundamentis complicationum ac transpositionum doctrina nouis praeceptis exstruitur, c. 1666) es ciencia general del siglo XVI y XVII que sirve para conocer las cosas más allá de su apariencia fenomenológica (conocer la estructura de la realidad) utilizando los elementos del lenguaje y la memoria: signos, imágenes, representaciones (Rossi, 1989). En el Breviculum de Karlsruhe, la alegoría explicatoria de la doctrina de Llull asciende por una escalera (otro lugar del conocimiento) hasta la Torre de la Fe y la Verdad. Breviculum ex artibus Raimundi Lulli electum de Tomas Le Myésier, 1321, Francia, Badische Landesbibliothek de Karlsruhe (Rubio, 1993: 57-65).

16 Llibre de Doctrina pueril, Pere Antoni Capó (imp.), Palma de Mallorca, 1736.

17 Pico della Mirandolla o Giordiano Bruno, luego Descartes o Bacon lo critican (Ausejo, 2004: 21-34).

18 Y en la filosofía hispana, como en J. Luis Vives (Egido, 1986: 25-66). 
Estas coincidencias se hacen patentes en su tratado de la Doctrina, comentado por Da Costa. La Gramática, para Llull, es también la puerta del saber, «portal per lo qual hom passa a saber les altres sciénces» (Doctrina, LXXIII, 3), y como se supone que la Gramática comparte las estructuras de la realidad, la Lógica deriva de ella y engloba el Trivium yendo de lo general a lo particular y supeditada a la ley moral: «Lógica es demostració de veres cozes e de falses» (LXXIII, 4). La Retórica, como arte de expresión, participa igualmente de todas las ciencias. El Quadrivium no puede tampoco desgajarse, ni tiene autonomía respecto al Trivium ${ }^{19}$. La Geometría luliana es pitagórica, para Elena Ausejo es una simplificación 'pseudomatemática' ajena a los conocimientos euclidianos. La Nova geometría se basa en las tres figuras (triángulo, círculo, cuadrado) que representan las correspondencias anagógicas del mundo divino, espiritual y humano, relacionadas con las faces de la Trinidad y sus atributos: Intelecto, Voluntad y Memoria. La Aritmética que la sustenta sirve básicamente para memorizar: «Aqueste Art es paraque los homens millor sapian retenir el nombre en la memoria y en la vista corporal, perque naturaleza es de la memoria primér olvidar moltas cosas qu'una». Con ella se halla la medida del cosmos y sus partes; es «departir un en molts», es decir, que reduce las cosas a algo definido por su forma, lugar y nombre para distinguirlas y clasificarlas como máscaras de los elementos del conocimiento del mundo. La memoria tiene que dominar la progresión aritmética para incrementar el saber (Doctrina, LXXIV, 2). Y como «molts homens ayha qui tenen memoria y no saben memorar» (Doctrina, LXXXIV, 21), Llull compuso unas 25 versiones de su Ars magna, un método para saber o visualizar todo. El Ars magna generalis es la más larga (c. 1274. Yates, 1954: 115-173) $)^{20}$.

«El tema de este arte es la respuesta a todas las preguntas, suponiendo que lo que se puede saber en general es formulable en el concepto (...) Establecemos en este Arte un alfabeto con el que podemos rellenar figuras y la combinación de los principios y de las reglas, con el objetivo de encontrar la verdad. Pues mediante una letra que puede tener muchas significaciones es el entendimiento mucho más universal en el comprender múltiples significaciones (...). Este

19 La Astronomía/logía de Llull es ciencia basada en los signos de los planetas, vinculados a la Música, la teoría de los humores y los elementos. A estas artes añade el Derecho, la Medicina y la Teología. (Da Costa, 2006: 164-131).

20 Arreglada en el Ars generalis ultima (c. 1302), abreviada en el Ars brevis (1308), también se expone en el Ars compendiosa inveniendi veritatem, el Arte demostrativa, el Ars praedicatione, el Liber refugio intellectus... La Biblioteca Cervantes ha publicado una antología de las obras de Llull. La transcripción de muchas de ellas ha sido editada por Butiñá (2012). Las 13 partes del Ars son: de alphabeto, de figuris, de definitionibus, de regulis, de tabula, de evacuatione tertia figurae, de multiplicatione quartae figurae, de mixtione principiorum, de novem subiectis, de aplicatione, de quaestionibus, de habituatione y de modo docendi hanc artem. 
alfabeto tiene que saberse de memoria, pues de otro modo no puede ser este arte bien utilizado ${ }^{21}$.

Llull intentaba formular la verdad a partir de las combinaciones que permiten los diseños geométricos perfectos. Su catálogo de formas lógicas y árboles cabalísticos se compone de figuras que buscan proporcionar definiciones directas de las cosas. Para los cabalistas cristianos, la demostración de que 3 son 1 deriva de un hecho que implica lo visual en las letras, trazos y números ${ }^{22}$. Los artefactos de Llull combinan estas figuras según reglas mecánicas para construir enunciados mediante algoritmos; son discos rotantes que hacen correspondencias cifradas entre formas y significados (Fig. 5) ${ }^{23}$. Se introduce el movimiento mecánico en el artefacto iconográfico para que una sola imagen pueda expresar distintos contenidos. Pero se puede llegar a deducciones falsas con este sistema, y por eso el alfabeto se combina con un cuadro lógico de correspondencias sujeto-atributo. Así se formulan enunciados partiendo de una misma regla y forma ${ }^{24}$.

21 Traducción del Ars magna en Kiinzei-Heiko, 1998: 89-107.

22 El Alef se compone de tres trazos (Muñiz, 1989: 145-153).

23 Ramón Llull, "Prima figura", Illuminati sacre pagine ... Raymundi Llull, Ars magna generalis et ultima, quarūcun q[ue] artium [et] scientarium ipsius Llull, assecutrix et clauigera [et] ad eas aditum faciliorē prebēs antehac nusq[uam] arti impressorie emüctius cōmendata, [et] per magistrum Bernardum la Vinheta artis illius fidelissimū interpretē elimata, Lugduni, per Jacobum Marechal calcographum, 1517, p. 10, BNE, R/40075.

24 En el Ars magna, los atributos divinos se representan en las letras, y a cada atributo le corresponde un principio, una pregunta fundamental, una entidad, una virtud y un vicio. Por ejemplo, a la letra E le corresponde: poder - principio - por qué - hombre - templanza - soberbia. 


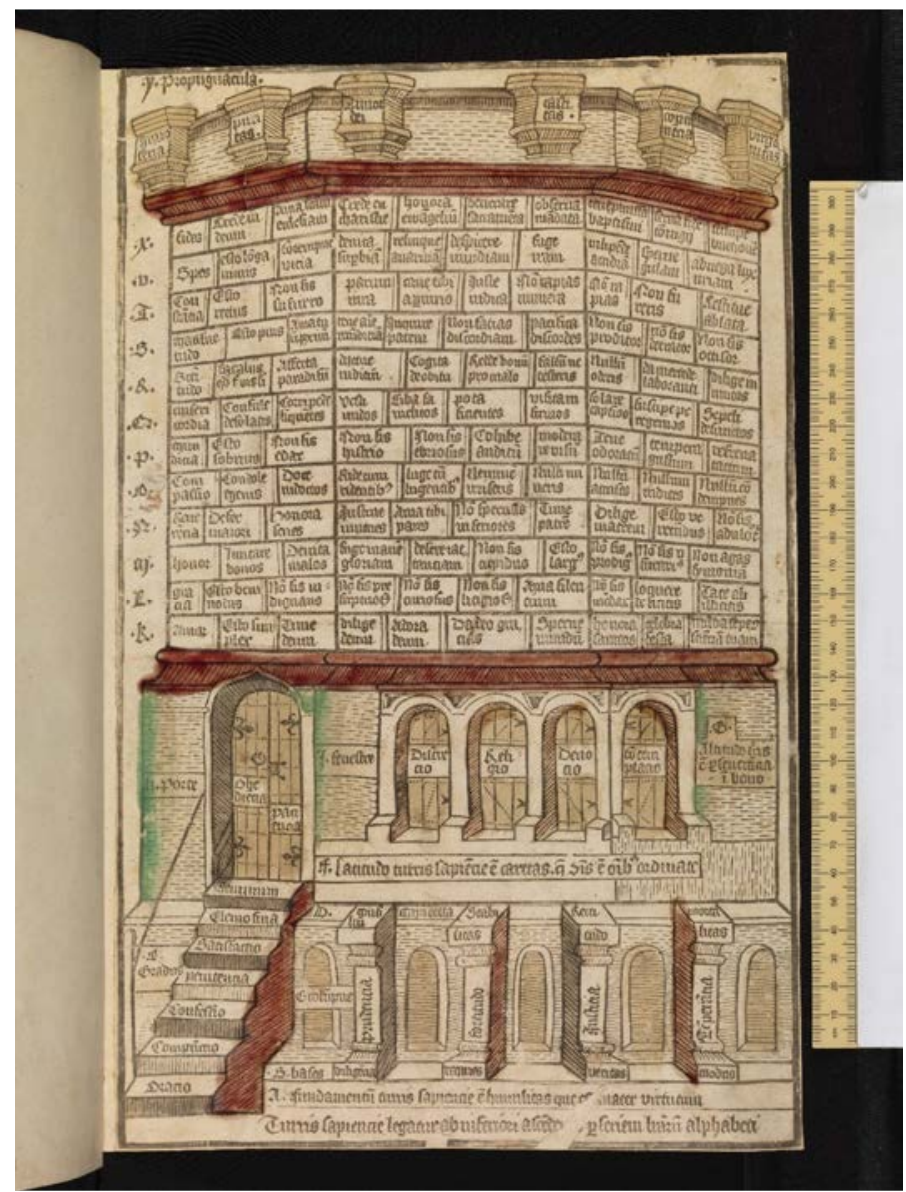

Fig. 5. Johannes Metensis, Turris sapientiae, c. 1474, Bodleian Library, University of Oxford, XYL-25, f. 1r.

La introducción del movimiento mecánico en la lógica combinatoria no es una aportación exclusiva de la obra de Llull. El invento atribuido a Guido d'Arezzo, la mano guidoniana, servía para ayudar a los cantores a memorizar y leer música con figuras pintadas en la palma, que se articulan como las falanges sobre las que están dispuestas, y se relacionan entre sí dependiendo de su ubicación y el movimiento de la otra mano, que las va señalando. En la máquina 
de Llull, unas partes se mueven respecto a otras como esos dedos, o las imágenes en la mente ${ }^{25}$.

Se ha insistido en que Llull diseñó 'máquinas lógicas' y no 'computadoras'; aun así, su invento intentaba sustituir el movimiento de la mente con artefactos visuales. Suponía que de este modo imitaba las estructuras de la realidad, de manera que el conocimiento metafísico compartiera su sistema con el retórico, el lógico, el aritmético, astronómico... y el Ars magna fuera la intersección de todas las artes y lenguajes.

Leibniz retomó la teoría luliana e ideó el Ars combinatoria (vid. nota 14). Ángela Muñiz ha subrayado que este ya partía de Euclides; no obstante, el algoritmo en la aritmética se transmitía en la Península desde hacía tiempo a través de los árabes. Según Savage-Smith, no hay conexión directa entre los «mapas de memoria» árabes del siglo IV al X y los posteriores Ars memoriae europeos, pero percibe su parecido razonable (2003: 121), y la obra de Llull es un puente posible: Wenzel ha detectado empleos de sus técnicas memorativas en la sermonaria (2015).

La teoría del Ars magna se ha estimado como valiosa muestra del interés medieval en las técnicas de formalización del lenguaje, difundida con posterioridad al siglo XIII, cuando las reglas escolásticas para recordar y estructurar las cosas en imágenes estaban más divulgadas, y está relacionado con la memoria artificial, no sólo a través de la Aritmética. Una de las influencias en la obra de Llull por esta parte viene de una rama particular del Ars memoriae: Ars notatoria ${ }^{26}$.

\subsection{MÁSCARAS PROHIBIDAS}

Para el autor del Ars Magna, como para el protagonista de Fausto, la máxima aspiración es adquirir un conocimiento absoluto que lleve a la perfección. Otra vía para conseguirlo es el Ars notoria o notatoria, prohibida por demoníaca y, sin embargo, practicada. Como el Ars magna, puede relacionarse, y hasta confundirse, con el Ars memoriae. La diferencia se ha resumido diciendo que el Ars notoria usa la magia, teniendo en cuenta las determinaciones religiosas y eclesiásticas de cada época y localidad. La técnica de este arte se atribuía a Salomón, cuya memoria custodiaba todos los saberes. Consistía en

25 Véase por ejemplo el tratado musical de Elias Salomon, c. 1274, conservado en la Biblioteca Ambrosiana de Milan (MS D.75, f. 6r).

26 El arte luliana se reivindica en relecturas de Pascal o Newton, que tenía en común con Leibniz, al parecer, un Ars magna en su biblioteca (Zweig, 1997: 20-29; Kiinzei-Heiko, 1998: 89-107; VVAA, 2011). Los estudiosos del Arte memorativa han abordado su obra en este sentido (Yates, 1954: 115-173) así como en relación al Arte notatoria (Perarnau, 1980: 223-227). 
interiorizar imágenes diagramáticas, notae: dibujos trascendentes que sirven para aprender las artes de los ancestros y predecir el futuro, lugares abstractos, como las tablas lulianas, donde se ubican ahora caracteres místicos en forma de palabras 'secretas' (hebreas, griegas, árabes, angélicas), verba ignota, para memorizarlas a través de su pronunciación repetida (el juego infantil que gustaba al pintor de vanguardia, Kandinsky) y la meditación en su forma y disposición (Láng, 2008: 87-93).

Los diagramas del Ars Notoria Sive Flores Aurei, copiado hacia 1225 en Francia, estaban atribuidos a Apollonio de Tyana, pitagórico de Capadocia que utilizaba nombres y geometrías para proporcionar, o prometer, conocimiento directo de las cosas (c. 25-100) (Fig. 7) ${ }^{27}$. Los primeros tratados conocidos son anónimos del siglo XII difundidos en distintas versiones perseguidas por los franciscanos, practicantes de artes memorativas para sus predicaciones ${ }^{28}$.

Pero las notorias se mezclaban con las didácticas canónicas ${ }^{29}$. Claire Fanger ha investigado acerca del Liber florum, escrito a inicios del siglo XIV por Jean de Morigny, subrayando que este benedictino vivía bajo el influjo del tímpano memorial de Chartres, ya que él mismo cuenta cómo le inspira aquella máscara del conocimiento que traspone en su 'tratado de las visiones' ${ }^{30}$. Se presentó como primer escritor de un Liber dictado por la Virgen, sustituto del Ars notoria, pero, aunque usaba para los nombres una lengua más reconocible, o menos sospechosa, mantuvo sus figuras abstractas. Rehízo el Liber varias veces intentando adaptarlo a la ortodoxia, cambiaba las figuras geométricas por imágenes de personajes bíblicos, pero su Nueva compilación fue quemada en París en 1323 (Fanger, 2010: 162).

27 Figura del Mellon MS 1, Beinecke Rare Book and Manuscript Library de la Yale University.

28 Julien Véronèse analiza prohibiciones oficiales del compendio de Alejandro de Hale (c. 1240) (2004: 637 ss.).

29 En los escriptorios monacales se coleccionaban argumentos a favor de diversas prácticas memorativas mágicas con la imagen (Page, 2013) que llegaron al renacimiento (Klaasen, 2013: 33 ss.). Véronèse encontró más de cincuenta copias medievales de variantes reconocibles del Ars notoria (2004).

30 Se conocen varias copias, en Bolonia, Biblioteca Comunal deli'Archiginnasio, A. 165 (16b. III. 5), o Augsburg, Staats-und Stadtbibliothek, 4 Cod. 55. (Fanger / Watson, 2004: 4-5; Fanger, 2010: 162). 


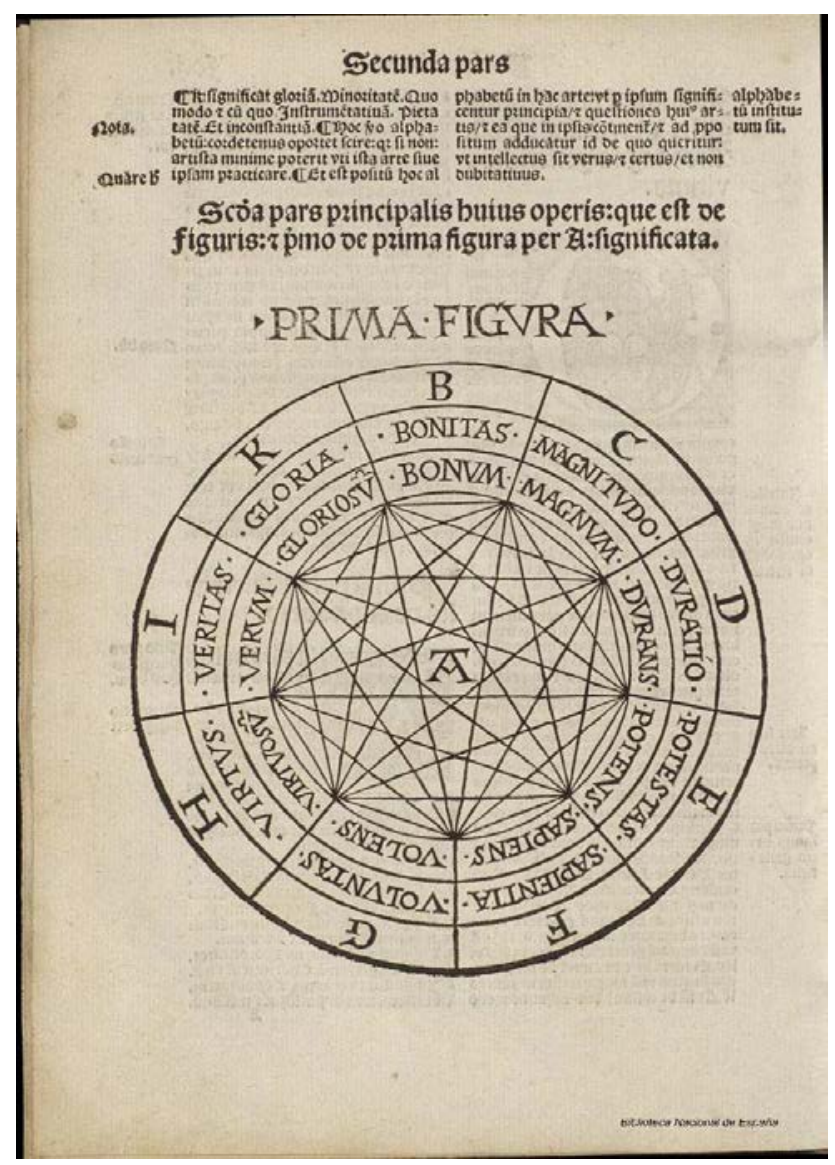

Fig. 6. Ramón Llull, "Prima figura", Illuminati sacre pagine... Raymundi Llull, Ars magna generalis et ultima, quarūcun q[ue] artium [et] scientarium ipsius Llull, assecutrix et clauigera [et] ad eas aditum faciliorē prebēs antehac nusq[uam] arti impressorie emūctius cōmendata, [et] per magistrum Bernardum la Vinheta artis illius fidelissimū interpretē elimata..., Lugduni, per Jacobum Marechal calcographum, 1517, Biblioteca Nacional de España, R/40075, p. 10.

En resumidas cuentas, en la Edad Media se utilizaban distintas técnicas visuales para estimular la memoria artificial, y se tacharon las que contradecían la dogmática oficial ofreciendo el saber de todas las artes en poco tiempo y con símbolos vacios de contenido. Condenar lo no-figurativo, si así pueden entenderse las notae y los verba ignota, era una manera de controlar el código de la representación. 
«96. Las prácticas Supersticiosas. Artículo 1: ¿Son ilícitas las prácticas de las artes notorias? (...) Respuesta: Que el arte notoria, además de ilícita, es ineficaz. Ilícita, porque hace uso de medios para adquirir la ciencia que carecen de todo valor y eficacia, tales como el examen atento de ciertas figuras, la pronunciación de palabras desconocidas y otros por el estilo. Tal arte no se sirve de tales medios como causas, sino como signos; pero no a modo de signos instituidos por Dios, como lo son los signos sacramentales (...) se deduce de esto que se trata de signos vacíos de todo contenido y que tienen que ver con pactos rituales para entrar en relaciones y alianza con los demonios (...) Es tal arte ineficaz para adquirir la ciencia, pues, como por medio de ella no se pretende alcanzarla de un modo connatural al hombre, o sea, por la investigación y aprendizaje, tal efecto, o se espera de Dios, o de los demonios. (...) Adquirir la ciencia es cosa buena; pero no adquirirla de modo indebido, y éste es el objetivo del arte notoria» ${ }^{31}$.

\subsection{TORRES ESCRITAS}

El uso mnemotécnico de las letras y los nombres conduce a otro tipo de producción: literatura que traspone lugares, más o menos determinada por la codificación del saber en símbolos y esquemas que representan la expresión e intensión de los elementos de un cosmos. Un locus memorativo, como una Turris sapientiae, puede revisitarse; se memoriza para más tarde recorrerse mentalmente, recolectar sus imágenes, contemplarlas y describirlas para componer una narración. Alfonso de la Torre pudo escribir de manera parecida uno de los primeros tratados de filosofía en romance: Visión deleytable de las artes y la filosofía (1440-1450). Se han reconocido ciertos parecidos de su obra con el viaje de Dante. Cuenta el camino del Entendimiento guiado por el Ingenio en su subida por las moradas de las Artes hasta llegar al Monte de la Verdad, la Sabiduría, la Razón, la Naturaleza. La descripción de la Visión va narrando la historia, trazando una ruta edificante sobre los edificios de las artes y conceptos personificados, representados en las xilografías ${ }^{32}$. El Entendimiento se detiene para examinar esos habitáculos y dialogar con los personajes. Transita por un lugar muy parecido a aquellas Torres del Saber, «paradigmas de arquitectura

31 Tomás de Aquino, Summa Theologiae, 2a-2ae, q. 96, art. 1.

32 Alfonso de la Torre, La visión deleytable, Salamanca, Universidad de Salamanca, 1991. Ver las ilustraciones del incunable [Visión deleitable] Comieça el tratado llamado visión deleytable de la phylosofia et de las otras sciencias compuesto por Alfonso de la Torre bachiller, Tolosa (de Languedoc), Juan Parix y Esteban Cleblat, 1489, Madrid, BNE, Inc/1806. 
escrita»-tomando la expresión de Calatrava y Nerdinger, (2010: 153)- escrita en imágenes.

Otro ejemplo elocuente de este imaginario se encuentra en el libro de Rocío Sánchez, Los rostros de las palabras, que aborda los encuentros de la retórica con las artes plásticas medievales:

«E en aquello que el trivio á de facer en la razón, la primera de todas las mercuriales ministras, que es la gramática, faze el cimiento de toda razón, e esto es cuemo qui faze casa (...) la dialéctica alça las parecdes en la razón; la retórica pinta e afremosa toda la obra e pone-l'de suso muy fremoso techo pintado a estrellas» ${ }^{33}$.

El edificio en construcción del Trivium se revisita en la corte de Alfonso X en un texto que elabora una imagen similar a la torre de Joan de Metz, o más bien, a la miniatura del códice de Lilienfeld ${ }^{34}$. Es otra arquitectura descrita que hace imaginar un edificio donde cada parte adquiere un sentido en función de las otras. El diseño ideal sigue siendo el de la torre orgánica y edificante, una figura muy recurrente en la didáctica.

Los elementos tectónicos de la arquitectura se pueden trasponer en narraciones descriptivas, como aquella, que explican sus términos metafóricos. Pero a veces las obras literarias encriptan los espacios del conocimiento, como hace la Lógica Memoriativa de Murner con las figuras plásticas. Ejemplo del caso puede ser la Cárcel de Amor de Diego de San Pedro, una alegoría literaria. Para acceder a la enseñanza de la torre que transita su protagonista desenvolviendo el relato, el lector ha de completar las claves del vocabulario simbólico que se utiliza y construir una imagen mental de lo que significa ${ }^{35}$. Podría relacionarse

33 General Estoria, II, cit. Sánchez, 2014: 14.

34 La Turris virtutum. El códice de Lilienfeld (c. 1355, lat. d.t. f. 248v) es uno de los cuatro manuscritos de este tipo que se conservan en las bibliotecas del monasterio de Lilienfeld en Austria, la de la Orden Piarist de Hungría, la Pierpont Morgan Library en New York y la Bibliothèque Nationale francesa, y han sido digitalizados en Konkordanz der Bildseiten der Handschriften von Udalricus Campililiensis (Ulrich von Lilienfeld), Concordantiae caritatis por Martin Roland $<$ www.univie.ac.at/paecht-archiv-wien/cc_html/cc-Tugend-2.html > [13/02/2016].

35 Se conservan muchas ediciones. En la BNE, entre otras, está la primera sevillana, de 1492, Inc/2134 p. 4-7: «(...) una torre de altura tan grande que me parecía llegar al cielo; era hecha por tal artificio, que de la estrañeza della comencé a maravillarme (...). El cimiento sobre que estava fundada era una piedra tan fuerte de su condición y tan clara de su natural qual nunca otra tal jamás avía visto, sobre la qual estavan firmados quatro pilares de un mármol morado muy hermoso de mirar. Eran en tanta manera altos que me espantava cómo se podian sostener; estava encima dellos labrada una torre de tres esquinas, la más fuerte que se puede contenplar; tenía en cada esquina, en lo alto della, una imagen de nuestra umana hechura, de metal, pintada cada una de su color: (...) vi travada con los mármoles dichos una escalera que llegava a la puerta de la torre, la qual tenía la entrada tan escura que parescía la sobida della a ningund onbre posible. Pero, ya deliberado, quise antes 
este tipo de obras con carmina figurata, poemas en imágenes (Sánchez 2014: 219), poemas visuales que se construyen a través de la descripción de un lugar y sus máscaras. Juan Calatrava ha señalado la gran divulgación del carmen figuratum de tipología turriforme en algunos textos del siglo XVII, donde las escaleras o columnas de la arquitectura moralizada no son los pilares de la Iglesia, virtudes o saberes de las artes, sino piernas de mujer o personificaciones de nobles importantes (Calatrava, 2010: 153).

\section{A MODO DE (IN)CONCLUSIÓN}

El arte de la memoria, originado en la retórica clásica, se instituye en la Edad Media como virtud y como arte de producción de iconografías, pero se diversifica en distintas teorías, técnicas y aplicaciones con similitudes en otras artes y géneros. Para Carrasco, producciones literarias como el Roman de la Rose de Guillaume de Lorris «plantean la interrogante sobre los posibles alcances de la escritura poética como soporte mnemotécnico, y sus interrelaciones en el campo del alegorismo medieval» (1999: 2). Otras composiciones literarias parecen responder a los efectos de las imágenes específicas de la memoria artificial, como la Cárcel de Amor, o la Visión Deleitable.

Si consideramos que la práctica mnemotécnica puede codificar un tipo de imaginería alegórica que se filtra en obras literarias difundidas en distintos ámbitos de la cultura, y ya que no se trata de un proceso interartístico unidireccional, desde el lado de los estudios visuales surgen las dudas correspondientes: ¿Hasta qué punto la tratadística memorativa, y la literatura alegórica relacionada con los productos para educación de la memoria, pueden afectar al modo en que se perciben imágenes, se elaboran métodos interpretativos y se generan programas iconográficos en artes plásticas no-mnemotécnicas? Algunas producciones visuales ajenas al arte de la memoria, y no siempre destinadas a una recepción individual, han sido aquí someramente pensadas a la luz de sus normas retóricas (iluminaciones de manuscritos, esculturas monumentales).

Se trataba de abrir alguna vía al estudio de las aplicaciones del arte de la memoria en relación con las intersecciones del arte plástico y la literatura, porque que el Ars memoriae enseña, precisamente, a ejercitar la memoria artística, es decir que sus lecciones y argucias mentales ayudan a descubrir los mecanismos de construcción y expresión de imágenes y sus funciones comunicativas en el lenguaje. Consiste en ejercitar la mente para configurar una topografía

perderme por sobir que salvarme por estar; y forcada mi fortuna, comencé la sobida», luego va topándose con puertas, guardianes, etc. (Deyermond/Parrilla, 1995: 6-7) 
imaginaria, persuasiva del recuerdo, capaz de condicionar imágenes técnicas estableciendo relaciones metafóricas que fundamentan códigos interpretativos. Este engranaje de imágenes y palabras se hace notar de distintos modos respecto al Ars memoriae como al Ars magna o el Arte notatoria.

En este sentido, estas artes pueden responder a cuestiones que interesan a las teorías semióticas contemporáneas, psicoanalíticas, antropológicas, fenomenológicas, acerca del funcionamiento de la memoria noética e hiponoética en la práctica artística y en la construcción historiográfica, como apuntábamos en el artículo anterior. Para la historia del arte el problema se refiere al estudio del desarrollo de la iconografía y las funciones didácticas de sus repertorios figurativos en diversos soportes, pero además permite extender las competencias del análisis iconológico a las producciones literarias y otras prácticas narrativas, pues el arte de la memoria requiere entender las imágenes no sólo como el cuerpo plástico en que se mediatiza un contenido semántico, también son ideas e imaginaciones que se instalan en palabras y gestos; la imagen como detonante incluso del sentimiento que motiva producciones del lenguaje. En definitiva, el estudio del arte memorativo puede fructificar en la investigación teórica de la re-presentación, en la dialéctica de lo consciente e inconsciente, lo natural y artificial, en el territorio ambiguo y transdisciplinar de las imágenes y la memoria visual; sus imágenes colectivas construyen la memoria histórica occidental.

La teoría memorativa suple en cierto modo la falta de referentes teóricos o tratados de retórica visual en la Edad Media, pues la memoria, para aquellos teóricos, era el vínculo entre el habla y la visión, la mente y el cuerpo. Una obra plástica o literaria no es del todo ajena al arte de la memoria si puede ser leída, pues la lectura es posible gracias a la memoria, fundamento del arte y del lenguaje. El llevar más allá este tipo de estudio puede colaborar a proporcionar la explicación que justifique la trasposición de normas de un medio de expresión verbal a la interpretación de los mecanismos de un medio visual en términos historiográficos. Este es uno de los mayores problemas de la investigación de los empleos comunicativos de las imágenes, un problema situado en un territorio transversal, para cuya exploración se hace necesario traspasar las divisiones y límites académicos de la historia del arte. 


\section{BIBLIOGRAFÍA}

AUSEJO, E., «La cuestión de la obra científico-matemática de Ramón Llull», Historia de las ciencias y de las técnicas, Español, L. et. al., (coords.), vol. 1, 2004, pp. 21-34.

BUTIÑÁ, J. (coord.), Los mundos de Ramón Llull, editorial UNED, 2012.

CALATRAVA, J. y NERDINGER, W. (eds.), Arquitectura escrita, Catálogo de la exposición del Círculo de Bellas Artes, Madrid, Ministerio de Cultura, 2010.

CARRASCO, R., «La Topografía Memorativa: Imágenes/ Alegorías de la Mujer Medieval en el Romance de la Rosa», Cyber Humanitatis, S.l., Enero, 1999. Disponible en:

$<$ http://www.cyberhumanitatis.uchile.cl/index.php/RCH/article/view/9241/9276> [última consulta 10/11/2017].

CARRUTHERS, M. J., The Book of Memory: A Study of Memory in Medieval Culture (1990), Cambridge, Cambridge University Press, 1992.

CARRUTHERS, M. J., «Thomas Bradwardine,'De memoria artificiale adquirenda'», The Journal of Medieval Latin, 2, 1992, pp. 25-43.

CARRUTHERS, M. J. /ZIOLKOWSKI, J. M., The medieval craft of Memory: An anthology of texts and pictures, Philadelphia, University of Pennsylvania Press, 2003.

COLEMAN, J., Ancient and Medieval memories: studies in the reconstruction of the past, Cambridge, Cambridge University Press, 1992.

DA COSTA, R., «Las definiciones de las siete artes liberales y mecánicas en la obra de Ramón Llull», Anales del seminario de historia de la filosofía, vol. 23, 2006, pp. 164-131.

DE LA FLOR, F. R., Emblemas. Lecturas de la imagen simbólica, Madrid, Alianza Forma, 1995.

EGIDO, A., «El Arte de la Memoria y ‘El Criticón’», Gracián y su época, Actas de la I Reunión de Filólogos Aragoneses: ponencias y comunicaciones, (1985), Zaragoza, Institución Fernando el Católico, 1986, pp. 25-66.

FANGER, C., «Sacred and secular knowledge systems in the 'ars notoria' and the 'Flowers of Heavenly Teaching' of John of Morigny», en A. Kilcher and P. Theisohn (eds.), Die Enzyklopädik der Esoterik: Allwissenheitsmythen und universalissenschaftliche Modelle in der Esoterik der Neuzeit, Munich, Wilhelm Fink Verlag, 2010, pp. 157-176.

FANGER, C. y WATSON, N., «Some further manuscripts containing copies of the Liber visionum by John of Morigny», Societas magica newsletter, $\mathrm{n}$. 12, 2004, pp. 4-5. 
FLORES MORADOR, F., «Eidetic grammar, Imagery, Order and History», Lund University, 2011, en Social science research network, pp. 1-14, disponible en: <http://archive.is/Js4hX\#selection-731.0-731.184> [10/11/2017].

GOMBRICH, E., Imágenes simbólicas. Estudios sobre el arte del Renacimiento, Madrid, Alianza, 1983.

KIINZEI-HEIKO, W., Luis Baz (trad.), «El Ars Generalis Ultima de Ramón Llull (estudios sobre un origen sereto de la teoría computacional moderna)», Revista Española de Filosofía Medieval, 5, 1998, pp. 89-107.

KLAASSEN, F., The transformations of Magic: Illicit learned magic in the Later Middle Ages and Renaissance, Philadelphia, Penn State Press, 2013.

LÁNG, B., "The Art of memory and magic (the ars memorativa and the ars notoria) », en Wójcik, R. (ed.) Culture of Memory in East Central Europe in the Late Middle Ages and the Early Modern Period, Poznan, Bibioteka Uniwersytecka, 2008, pp. 87-93.

MITTELBERG, I., «The visual memory of Grammar, Iconographical and metaphorical insights», AISB, 99 Symposium on Metaphor, artificial intelligence and cognition, (1999), 2002, pp. 69-89, disponible en <metaphoric.de $>[09 / 11 / 2017]$.

MORCILlO ROMERO, J. J., El Ars Memorativa de G. Leporeo (Estudio, edición crítica, traducción, notas e índices), tesis doctoral, Programa de doctorado en Estudios Filológicos, Departamento de Ciencias de la Antigüedad, Universidad de Extremadura, 2015.

MUÑIZ, Á., «Ramón Llull y el simbolismo de la cábala», Acta poética, primavera-otoño, 1989, pp. 145-153.

MUÑOZ, E., «Del arte del recuerdo en imágenes (I)», Norba, Revista de Arte, 37, 2017, pp. 71-90.

PAGE, S., Magic in the Cloister: Pious Motives, Illicit Interests, and Occult Approaches to the Medieval Universe, Philadelphia, Penn State Press, 2013.

PERARNAU, J., «Entorn de 1' 'Ars No(ta)toria' de Ramon Llull», Revista catalana de Teología, Universidad de Barcelona, 5, 1980, pp. 223-227.

REININK, A. W. y STUMPEL, J. (eds.), Memory \& Oblivion: Proceedings of the XXIXth International Congress of the History of Art, (1996), Amsterdam, Springer Science \& Business Media, 2012.

ROSSI, P., Clavis universalis: el arte de la memoria y la lógica combinatoria de Lulio a Leibniz, México, Fondo de Cultura Económica de México, 1989.

RUBIO TOVAR, J., «El castillo en la literatura», en Cámara, A. (ed.), Castillos, fortificaciones y recintos amurallados de la Comunidad de Madrid, 
Madrid, Dirección General de Patrimonio Cultural, Comunidad de Madrid, Consejería de Educación y Cultura, 1993, pp. 57-65.

SÁNCHEZ AMEIJEIRAS, R. (2014): Los rostros de las palabras. Imágenes y teoría literaria en el Occidente medieval, Madrid, Akal, 2014.

SAVAGE-SMITH, E., «Memory and maps», en Madelung, W. et. al. (eds.) Culture and Memory in medieval Islam, Londres, I.B. Tauris, 2003.

SIEGEL, S., Tabula: Figuren der Ordnung um 1600, Berlin, Akademie Verlag, 2009.

VÉRONÈSE, J., L'Ars notoria au Moyen Âge et à l'époque moderne. Étude d'une tradition de magie théurgique (XII ${ }^{e}$ XVII ${ }^{e}$ siècle), Nanterre, Université Paris X Nanterre, 2004.

VV. AA., Alexander Fidora, Carles Sierra (eds.), Ramon Llull: From the Ars Magna to Artificial Intelligence, Barcelona, Artificial Intelligence Research Institute, IIIA Consejo Superior de Investigaciones Científicas, 2011. Disponible en: <http://www.iiia.csic.es/library> [10/11/2017].

WENZEL, S. (2015): Medieval Artes Praedicandi, a synthesis of scholastic sermon structure, Toronto, University of Toronto Press, 2015.

YATES, F. A., "The Art of Ramon Lull: An Approach to It through Lull's Theory of the Elements», Journal of the Warburg and Courtauld Institutes, vol. 17, n. 1/2, 1954, pp. 115-173.

YATES, F. A., El Arte de la Memoria, (1966a), Madrid, Siruela, 2005.

YATES, F. A.: «New Light on the Globe Theater», New York Review of Books, 1966b, 26 de Mayo, s.p. Disponible en: <http://www.nybooks.com/articles/1966/11/17/the-globe-theater/ > [03/11/2017].

ZWEIG, J., «Ars combinatoria. Mystical systems, procedural art, and the computer», Art Journal, 56, 3, 1997, pp. 20-29.

\section{Elena Muñoz Gómez}

Departamento de Historia del Arte y Bellas Artes

Facultad de Geografía e Historia

Universidad de Salamanca

Calle Cervantes, s.n.

37001 Salamanca (España)

https://orcid.org/0000-0002-4869-1790

celenia@usal.es 